\title{
Peningkatan Kegiatan Dinas Jaga Mesin pada Pengoperasian Mesin Penggerak Utama pada KM. Hasil Melimpah 18
}

\author{
Increased Activities of Watchkeeping in the Operation of the Marine Engine at \\ Hasil Melimpah 18 Vessel
}

\author{
I Made Aditya Nugraha1, Rasdam², Resky Amalia Rajab ${ }^{2}$ \\ ${ }^{1}$ Mekanisasi Perikanan, Politeknik Kelautan dan Perikanan, Kupang, NTT, 85351, Indonesia \\ ${ }^{2}$ Teknik Penangkapan Ikan, Politeknik Kelautan dan Perikanan Kupang, NTT, 85351, Indonesia \\ *Korespondensi: made.nugraha@kkp.go.id
}

\begin{abstract}
ABSTRAK
Kegiatan dinas jaga adalah suatu pekerjaan jaga yang dilakukan di kapal atau di pelabuhan untuk menciptakan situasi dan kondisi agar aman dan terkendali selama 24 jam yang dilakukan dengan tujuan urusan pekerjan supaya terciptanya keselamatan dan keamanan saat sedang bertugas. KM. Hasil Melimpah 18 tergolong dalam kapal perikanan yang bertipe khusus hanya untuk menampung muatan ikan dan tidak melaksanakan operasi penangkapan. Dalam upaya pencapaian tujuan dinas jaga yang lebih baik dilakukan suatu kajian terkait evaluasi kegiatan dinas jaga mesin pada pengoperasian mesin penggerak. Dari hasil observasi diperlukan adanya peningkatan kegiatan dinas jaga mesin pada pengoperasian mesin penggerak utama. Hal ini perlu dilakukan untuk meningkatkan pelaksanaan sebelum dan sesudah mesin dioperasikan, dan dinas jaga mesin pada saat mesin beroperasi. Peningkatan kegiatan dinas jaga mesin pada pengoperasian mesin penggerak utama dapat dilakukan dengan adanya beberapa peningkatan dikegiatan persiapan, pengoperasian, dan tugas jaga. Pada kegiatan persiapan diperlukan peningkatan pada ketersediaan peralatan K3, logbook, dan suku cadang sesuai kebutuhan. Pada kegiatan pengoperasian diperlukan peningkatan ketersediaan peralatan K3, alat komuniasi, dan panel listrik. Pada kegiatan tugas jaga diperlukan peningkaktan pada ketersediaan jadwal dinas jaga, jurnal harian mesin, dan alat ukur. Pentingnya pengontrolan secara berkala pada saat mesin sedang beroperasi merupakan tugas dinas jaga. Kerusakan mesin bisa saja terjadi apabila petugas dinas jaga melakukan suatu kelalaian kerja sehingga ini adalah tanggung jawab yang besar.
\end{abstract}

Kata kunci: Dinas jaga mesin; pengoperasian mesin penggerak kapal; mesin kapal

\begin{abstract}
Watchkeeping is guard work carried out on ships or in ports to create situations and conditions to be safe and under control for 24 hours carried out with the aim of work affairs in order to create safety and security while on duty. Hasil Melimpah 18 Vessel is classified as a fishing vessel of a special type only to accommodate fish cargo and does not carry out fishing operations. In an effort to achieve the goal of watchkeeping, a study is carried out related to the evaluation of the activities of the watchkeeping in the operation of the machine. From the results of observations, it is necessary to increase the activities of the watchkeeping in the operation of the main engine. This needs to be done to improve the performance before and after the machine is operated, and the watchkeeping when the machine is operating. The increase in the activities of the watchkeeping in the operation of the main engine can be done by several improvements, such as in the preparation, operation, and watchkeeping duty activities. In preparation activities, it is necessary to increase the availability of OHS equipment, logbooks, and spare parts as needed. In operating activities,
\end{abstract}


it is necessary to increase the availability of OHS equipment, communication tools, and electrical panels. In watchkeeping duty activities, it is necessary to increase the availability of the watchkeeping schedule, machine daily journals, and measuring tools. Periodic control while the machine is operating is very important. The watchkeeper must have a big responsibility because machine damage can occur if the duty officer on duty commits negligence.

Keywords: Watchkeeping; operation of ship engines; ship engine

\section{PENDAHULUAN}

Kapal perikanan sebagai salah satu sarana pemanfaatan sumber daya yang ada harus senantiasa dalam keadaan layak pakai (Desnanjaya et al., 2021). Kondisi layak pakai ini mencakup faktor teknis dan manajemen secara komprehensif. Salah satu faktor pendukung kelayakan kapal perikanan adalah dengan senantiasa memperhatikan kondisi permesinan secara umum, dan mesin induk pada khususnya (Hidayat et al., 2019; Kundori, 2020; Mustain, 2020; Setiono \& Mudiyanto., 2010; Suwardjo et al., 2017; Utomo, 2020). Kondisi mesin induk yang baik memiliki peranan yang cukup penting dalam menunjang kegiatan operasional kapal (Nugraha, 2020; Suwardjo et al., 2017; Utomo, 2020).

Kegiatan dinas jaga adalah suatu pekerjaan jaga yang dilakukan di kapal atau di pelabuhan untuk menciptakan situasi dan kondisi agar aman dan terkendali selama 24 jam yang dilakukan dengan tujuan urusan pekerjaan supaya terciptanya keselamatan dan keamanan saat sedang bertugas (Antoro et al., 2018; Mawardi, 2021; Suwardjo et al., 2017). Pelaksanaan dinas jaga dilakukan oleh petugas jaga di kapal pada waktu kapal berlayar maupun kapal sedang berlabuh dan diatur oleh peraturan Standart of Training Certification And Watchkeeping (STCW) (Gundić et al., 2020; Kim \& Mallam, 2020; Mawardi, 2021). Tanggung jawab perwira yang melaksanakan tugas jaga mesin untuk keselamatan dan efisiensi pengoperasian dari pemeliharaan mesin yang mempengaruhi keselamatan kapal dan juga bertanggung jawab dalam pemeriksaan, pengoperasian dan pengujian peralatan yang dibawah tanggung jawab tugas jaga kamar mesin. Personal tugas jaga mesin harus memenuhi syarat sesuai SOLAS 74, yaitu memiliki pengetahuan yang memadai tentang fungsi dan cara kerja permesinan di atas kapal dan bagian terkait masingmasing, mengerti prinsip kerja yang benar, memiliki pengetahuan dan keterampilan yang memadai dalam penanggulangan keadaan darurat dan pencemaran lingkungan laut (Antoro et al., 2018; Kurniawan, A. et al., 2018; Nugrahaet et al., 2021; Pasyah \& Adhitya, 2020; Setiono \& Mudiyanto, 2010; Suganjar \& Hermawati, 2019).

Dalam upaya pencapaian tujuan di atas dilakukan upaya peningkatan kegiatan dinas jaga mesin pada pengoperasian mesin penggerak utama pada KM. Hasil Melimpah 18 di Pelabuhan Perikanan Samudera Nizam Zachman Jakarta. Hasil observasi ditemukan beberapa kekurangan pada tahap persiapan, pengoperasian dan kegiatan dinas jaga. Dari hasil observasi di kapal diperlukan adanya peningkatan kegiatan dinas jaga mesin pada pengoperasian mesin penggerak utama. Hal ini perlu dilakukan untuk meningkatkan pelaksanaan sebelum dan sesudah mesin dioperasikan, dan dinas jaga mesin pada saat mesin beroperasi. Pengontrolan secara berkala pada saat mesin sedang beroperasi adalah hal yang sangat penting. Petugas dinas jaga harus mempunyai tanggung jawab yang besar karena kerusakan mesin bisa saja terjadi apabila petugas dinas jaga melakukan suatu kelalaian kerja. 


\section{METODE PENELITIAN}

Kegiatan penelitian ini dilaksanakan pada tanggal 16 November 2020 sampai dengan 16 Mei 2021 pada KM. Hasil Melimpah 18. Kegiatan ini berada di Pelabuhan Perikanan Samudera dan di daerah penangkapan.

Penelitian ini merupakan penelitian deskriptif yang mengambarkan kegiatan dinas jaga mesin yang terjadi pada kapal penampung hasil tangkapan. Data diperoleh dengan metode observasi, studi literatur, dan wawancara. Wawancara dilakukan dengan memberikan beberapa pertanyaan sehubungan kegiatan dinas jaga di atas kepal kepada Nahkoda, Mualim I, KKM, Masinis I, dan 9 orang ABK.

\section{HASIL DAN PEMBAHASAN}

KM. Hasil Melimpah 18 tergolong dalam kapal perikanan yang bertipe khusus hanya untuk menampung muatan ikan dan tidak melaksanakan operasi penangkapan. Pada dasarnya setiap kapal mempunyai kekurangan dan kelebihan, dari segi bentuk, ukuran, bahkan kegunaan. Pada kapal KM. Hasil Melimpah 18 yang dikategorikan sebagai kapal penampung ikan terdapat beberapa prosedur yang kurang sesuai, terutama pada bagian permesinan kapal dimulai dari kebersihan kamar mesin, keamanan dan keselamatan kerja yang masih kurang dari standar kelayakan kapal.

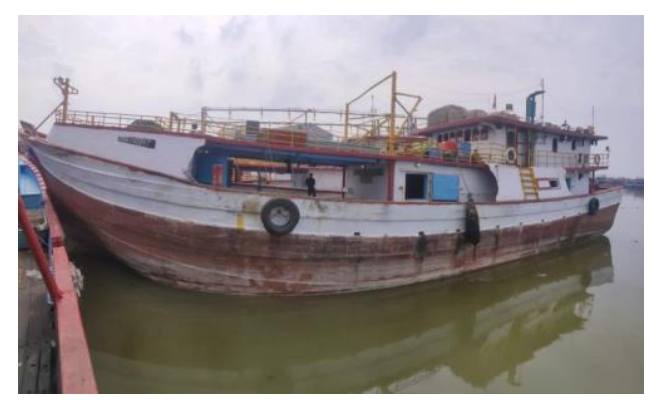

Gambar 1. KM. Hasil Melimpah 18

\section{Spesifikasi Kapal}

Tabel 1. Data Kapal KM. Hasil Melimpah 18

\begin{tabular}{ll}
\hline Data Kapal & Spesifikasi \\
\hline Nama Kapal & KM. Hasil \\
& Melimpah 18 \\
Kategori & Kapal Perikanan \\
Tipe & Kapal Penampung \\
& Ikan \\
Bendera & Indonesia \\
GT & 163 GT \\
Tahun Pembuatan & 2021 \\
Tanda Selar & Cilacap/QT.163 \\
& No. 976/QA \\
Muatan & Ikan \\
& Marlin, Cuna \\
& cumi \\
Bahan $\quad$ Utama & Kayu \\
Kapal & \\
Panjang & $28 \mathrm{~m}$ \\
Lebar & $8,45 \mathrm{~m}$ \\
Dalam & $3,15 \mathrm{~m}$ \\
Peggerak Utama & Mesin Diesel \\
Jumlah ABK & 17 \\
\hline
\end{tabular}

Tabel 2. Spesifikasi Mesin Penggerak Utama

\begin{tabular}{ll}
\hline Data Mesin & Spesifikasi \\
\hline Nama Mesin & Mitsubishi 10DC \\
& II \\
No. Seri Mesin & 375829 \\
Tipe & Enggine in board \\
Daya & 440 PK \\
Jumlah Silinder & 10 silinder \\
Bahan Bakar & Solar \\
\hline
\end{tabular}

\section{Peningkatan Pada Kegiatan Persiapan}

Kegiatan persiapan yang dilakukan di kamar mesin adalah kunci utama yang harus selalu dilaksanakan sebelum memulai tahap pengoperasian. Jika dalam hal persiapan kurang sempurna maka akan timbul resiko yang mungkin terjadi saat mengoperasikan mesin penggerak utama. Hasil observasi dan evaluasi kegiatan persiapan pada kapal KM. Hasil Melimpah 18 dapat dilihat pada Tabel 3. 
Tabel 3. Evaluasi Kegiatan Persiapan KM. Hasil Melimpah 18

\begin{tabular}{ll}
\hline \multicolumn{1}{c}{ Kegiatan } & \multicolumn{1}{c}{ Evaluasi } \\
\hline Pidak memiliani & Diperlukan alat \\
alat keselamatan & keselamatan \\
kerja yang lengkap & kerja yang \\
sesuai standar & lengkap dan \\
perkapalan & sesuai dengan \\
& standar \\
& perkapalan \\
Tidak adanya & Diperlukan \\
perhitungan bahan & logbook yang \\
bakar kebutuhan & berfungsi untuk \\
trip sesuai & mengetahui \\
pelayaran & penggunaan \\
& bahan bakar \\
Tidak adanya & Diperlukan \\
jurnal harian, & logbook harian \\
sehingga tidak & tentang mesin \\
memiliki dokumen & kapal untuk \\
tertulis tentang & mengetahui \\
keadaan mesin & kondisi mesin \\
setelah & kapal setiap hari \\
dioperasikan & \\
sebelumnya & \\
Tidak adanya suku & Diperlukan \\
cadang yang & persiapan suku \\
dibawa untuk & cadang sesuai \\
perjalanan & kebutuhan \\
pelayaran & sebelum \\
& melakukan \\
Kurangnya & pelayaran \\
pengetahuan ABK & Diikutkan \\
mesin tentang & pelatihan \\
permesinan itu & workshop \\
sendiri & tentang \\
& permesinan \\
kapal
\end{tabular}

\section{Peningatan Pada Kegiatan Pengopera- sian}

Pengoperasian mesin harus dilakukan dengan posedur yang baik dan benar agar tidak terjadi kerusakan pada mesin atau kecelakaan pada petugas yang mengoperasikan. Pada kapal KM. Hasil Melimpah 18 tahap pengoperasian masih menggunakan dinamo start dan dihidupkan secara manual menggunakan kabel yang dihubungkan secara langsung.
Tabel 4 adalah hasil observasi dan evaluasi kegiatan pengoperasian pada kapal KM. Hasil Melimpah 18.

Tabel 4. Evaluasi Kegiatan Pengoperasian

\begin{tabular}{ll}
\hline \multicolumn{1}{c}{ Kegiatan } & \multicolumn{1}{c}{ Evaluasi } \\
\hline Pidak adanya & Diperlukan \\
sarung tangan & perlengkapan K3 \\
keselamaan & yang sesuai \\
sebagai pengaman & dengan kegiatan \\
dalam menaikkan & di dalam kapal. \\
tuas aki & \\
penghubung listrik & \\
dan & \\
menghubungkan & \\
kabel ke dinamo & \\
start & \\
Tidak adanya & Diperlukan alat \\
radio komunikasi & komunikasi \\
dari kamar mesin & berupa radio \\
ke anjungan & untuk \\
sehinggaa tidak & mempermudah \\
dapat mengetahui & koordinasi dari \\
apakah handle gas & dan menuju \\
sudah berada & kamar mesin dan \\
diposisi jalan atau & anjungan \\
belum & \\
Tidak adanya & Diperlukan panel \\
panel untuk & listrik agar lebih \\
mematikan mesin & aman untuk \\
induk, dan hanya & menghidupakan \\
menggunakan & dan mematikan \\
manual stop & mesin \\
power & \\
\hline
\end{tabular}

\section{Peningkatan Pada Kegiatan Tugas Jaga}

Pengontrolan secara berkala pada saat mesin sedang beroperasi adalah hal yang sangat penting. Petugas dinas jaga harus mempunyai tanggung jawab yang besar karena kerusakan mesin bisa terjadi jika petugas dinas jaga melakukan suatu kelalaian kerja. Tabel 5 adalah hasil observasi dan evaluasi kegiatan tugas jaga pada KM. Hasil Melimpah 18. 
Tabel 5. Evaluasi Kegiatan Tugas Jaga

\begin{tabular}{|c|c|}
\hline $\begin{array}{c}\text { Kegiatan Tugas } \\
\text { Jaga }\end{array}$ & Evaluasi \\
\hline $\begin{array}{l}\text { Tidak adanya sistem } \\
\text { pergantian dinas } \\
\text { jaga mesin yang } \\
\text { teratur }\end{array}$ & $\begin{array}{l}\text { Diperlukan } \\
\text { jadwal dinas } \\
\text { jaga }\end{array}$ \\
\hline $\begin{array}{l}\text { Tidak adanya jurnal } \\
\text { harian mesin, } \\
\text { sehingga tidak ada } \\
\text { catatan riwayat } \\
\text { keadaan mesin } \\
\text { selama beroperasi }\end{array}$ & $\begin{array}{l}\text { Diperlukan } \\
\text { jurnal harian } \\
\text { untuk } \\
\text { mengetahui } \\
\text { keadaan mesin } \\
\text { selama } \\
\text { beroperasi }\end{array}$ \\
\hline $\begin{array}{l}\text { Tidak adanya alat } \\
\text { bantu pada mesin } \\
\text { seperti pengukur } \\
\text { tekanan dan } \\
\text { pengukur temperatur } \\
\text { mesin, sehingga } \\
\text { petugas dinas jaga } \\
\text { harus mengontrol } \\
\text { mesin secara manual } \\
\text { tanpa bantuan alat } \\
\text { bantu ukur tekanan } \\
\text { ataupun temperatur }\end{array}$ & $\begin{array}{l}\text { Diperlukan } \\
\text { beberapa alat } \\
\text { ukur untuk } \\
\text { mendukung } \\
\text { pengukuran di } \\
\text { dalam kamar } \\
\text { mesin, seperti } \\
\text { termometer } \\
\text { dan pressure } \\
\text { gauge }\end{array}$ \\
\hline Tidak adanya & Diperlukan \\
\hline $\begin{array}{l}\text { kepastian seberapa } \\
\text { jauh kapal berlayar } \\
\text { dan mesin } \\
\text { beroperasi, sehingga } \\
\text { menyulitkan } \\
\text { petugas dinas jaga } \\
\text { mesin untuk } \\
\text { menentukan kapan } \\
\text { dilakukannya } \\
\text { perawatan berkala } \\
\text { pada komponen- } \\
\text { komponen mesin }\end{array}$ & $\begin{array}{l}\text { logbook untuk } \\
\text { mendukung } \\
\text { kegiatan } \\
\text { perawatan } \\
\text { mesin }\end{array}$ \\
\hline
\end{tabular}

Hal-hal tersebut seharusnya menjadi perhatian khusus karena keselamatan kerja adalah kepentingan yang harus selalu diutamakan. Pelayaran kapal KM. Hasil Melimpah 18 terbilang sangat jauh, sehingga jika terjadi kerusakan dalam masa pelayaran maka akan menjadi permasalahan yang sangat sulit untuk di selesaikan.

Peningkatan dari alat pengukuran dapat menggunakan mikrokontroler untuk dapat mengetahui kondisi mesin secara langsung. Pemanfaatan ini telah banyak dipergunakan dalam kehidupan seharihari, seperti mematikan dan menghidupkan mesin, mengetahui kondisi lingkungan, dan lain sebagainya (Desnanjaya et al., 2021; Desnanjaya \& Nugraha, 2021; Mahardiananta et al., 2021). Pemanfaatan ini tentunya akan lebih sangat membantu tanpa harus turun langsung ke kamar mesin.

\section{KESIMPULAN}

Peningkatan kegiatan dinas jaga mesin pada pengoperasian mesin penggerak utama pada KM. Hasil Melimpah 18 dapat dilakukan dengan adanya beberapa peningkatan dikegiatan persiapan, pengoperasian, dan tugas jaga. Pada kegiaatan persiapan diperlukan peningkatan pada ketersediaan peralatan K3 yang lengkap dan sesuai dengan standar perkapalan, logbook untuk mengetahui penggunaan bahan bakar dan pencataan harian mesin. Pada kegiatan pengoperasian diperlukan peningkatan ketersediaan peralatan K3 yang sesuai dengan kegiatan di dalam kapal, alat komuniasi, dan panel listrik untuk keamanan dalam menghidupkan dan mematikan mesin. Pada kegiatan tugas jaga diperlukan peningkaktan pada ketersediaan jadwal dinas jaga, jurnal harian mesin, dan alat ukur.

Pentingnya pengontrolan secara berkala pada saat mesin sedang beroperasi merupakan tugas dinas jaga. Kerusakan mesin bisa saja terjadi apabila petugas dinas jaga melakukan suatu kelalaian kerja sehingga ini adalah tanggung jawab yang besar

\section{UCAPAN TERIMA KASIH}

Terima kasih kepada Kementerian Kelautan dan Perikanan Republik Indonesia dan Politeknik Kelautan dan Perikanan Kupang dalam mendukung penelitian ini. 


\section{DAFTAR PUSTAKA}

Antoro, D., Purwantini, S., \& Ikhsannudin, M.A. (2018). Analisis peningkatan dinas jaga di daerah rawan guna meningkatkan keamanan pada kapal mt. Sei pakning. Dinamika Bahari, 8(2). https://doi.org/10.46484/db.v8i2.70

Desnanjaya, I. G. M. N., \& Nugraha, I. M. A. (2021). Portable waste capacity detection system based on microcontroller and website. Journal of Physics: Conference Series, 1810(1).

https://doi.org/10.1088/17426596/1810/1/012001

Desnanjaya, I. G. M. N., Nugraha, I. M. A., \& Hadi, S. (2021). Sistem Pendeteksi Keberadaan Nelayan Menggunakan GPS Berbasis Arduino. Jurnal Sumberdaya Akuatik Indopasifik, 5(2). https://doi.org/10.46252/jsai-fpikunipa.2021.Vol.5.No.2.143

Gundić, A., Vujičić, S., Maglić, L., \& Ivanišević, D. (2020). Methods for demonstrating a competence and criteria for evaluating a competence in stcw convention. Pomorstvo, 34 (2). https://doi.org/10.31217/p.34.2.5

Hidayat, E. A., Iskandar, B. H., Purwangka, F., \& Soeboer, D. A. (2019). Pola Penggunaan Pelumas Pada Mesin Kapal Nelayan Di Pangkalan Pendaratan Ikan (Ppi) Kota Kendari. ALBACORE Jurnal Penelitian Perikanan Laut, 3(1). https://doi.org/10.29244/core.3.1.85 $-93$

Kim, T. eun, \& Mallam, S. (2020). A Delphi-AHP study on STCW leadership competence in the age of autonomous maritime operations. WMU Journal of Maritime Affairs, 19(2).

https://doi.org/10.1007/s13437-02000203-1

Kundori. (2020). Strategi Persiapan Pemeriksaan Annual Survey oleh Surveyor Biro Klasifikasi di Kamar Mesin Kapal. Majalah Ilmiah Gema
Maritim, 22(1).

https://doi.org/10.37612/gema-

maritim.v22i1.49

Kurniawan, A., Purwantini, S., \& Palapa, A. (2018). Analisis fix overtime untuk meningkatkan kinerja dinas jaga abk kapal MT. Sepinggan di PT. Pertamina (Persero) Perkapalan Jakarta. Dinamika Bahari, 9(1). https://doi.org/10.46484/db.v9i1.83

Mahardiananta, I. M. A., Nugraha, I. M. A., Arimbawa, P. A. R., \& Prayoga, D. N. G. T. (2021). Saklar Otomatis Berbasis Mikrokontroler Untuk Mengurangi Penggunaan Energi Listrik. Jurnal RESISTOR (Rekayasa Sistem Komputer), 4(1). https://doi.org/10.31598/jurnalresist or.v4i1.759

Mawardi, K. (2021). Pengaturan Pelaksanaan Dinas Jaga di Kapal Sesuai STCW 1978 as Amended 2010. Majalah Ilmiah Bahari Jogja, 19(1).

https://doi.org/10.33489/mibj.v19i1. 260

Mustain, I. (2020). Penurunan Tekanan pada Pompa Air Laut pada Mesin Induk Kapal. Majalah Ilmiah Gema Maritim, 22(1). https://doi.org/10.37612/gemamaritim.v22i 1.48

Nugraha, I.M.A. (2020). Penggunaan Pembangkit Listrik Tenaga Surya Sebagai Sumber Energi Pada Kapal Nelayan: Suatu Kajian Literatur. Jurnal Sumberdaya Akuatik Indopasifik, 4(2). https://doi.org/10.46252/jsai-fpikunipa.2020.vol.4.no.2.76

Nugraha, I.M.A., Luthfiani, F., Siregar, J.S.M., \& Tambunan, K. (2021). Pelatihan Perawatan dan Perbaikan Motor Diesel Satu Silinder Bagi Masyarakat Desa Tablolong Kupang Barat Nusa Tenggara Timur. Jurnal Panrita Abdi, 5(4), 659-668. https://doi.org/https://doi.org/10.20 956/pa.v5i4.12439

Pasyah, A. C., \& Adhitya, R. (2020). Analisis Kesesuaian Alat Keselamatan Jiwa Sesuai Dengan Solas 1974/1978 As Amended Pada 
Kapal-Kapal Cement Carrier Di PT. Pelayaran Tonasa Lines. Prosiding Seminar Pelayaran Dan Teknologi Terapan, 2(1). https://doi.org/10.36101/pcsa.v2i1.1 40

Setiono, B. A., \& Mudiyanto. (2010). Pengaruh Safety Equipment Terhadap Keselamatan Berlayar. Aplikasi Pelayaran Dan Kepelabuhan, 1.

Suganjar, S., \& Hermawati, R. (2019). Peran Designated Person Ashore (DPA) Dalam Pengoperasian Kapal Yang Aman Sesuai Ketentuan Nasional Dan Internasional. Jurnal Sains dan Teknologi Maritim, 20(1). https://doi.org/10.33556/jstm.v20i1. 212

Suwardjo, D., Haluan, J., Jaya, I., \& Poernomo, S. H. (2017). Keselamatan Kapal Penangkap Ikan, Tinjauan Dari Aspek Regulasi Nasional dan Internasional. Jurnal Teknologi Perikanan Dan Kelautan, 1(2).

https://doi.org/10.24319/jtpk.1.1-13

Utomo, B. (2020). Hubungan Antara Konsumsi Bahan Bakar dengan Berbagai Perubahan Kecepatan pada Motor Diesel Penggerak Kapal. Jurnal Rekayasa Mesin, 15(2). https://doi.org/10.32497/jrm.v15i2. 1957 
